\title{
An atypical presentation of cerebral fat embolism
}

\author{
Ioana Ion $^{1 *}$, Teodora Parvu ${ }^{1}$, Cyril Dumain ${ }^{2}$, Cyril Dargazanli ${ }^{3}$ and Dimitri Renard ${ }^{1}$ \\ ${ }^{1}$ Department of Neurology, CHU Nîmes, Univ Montpellier, Nîmes, France \\ ${ }^{2}$ Department of Internal Medicine, CHU Nîmes, Univ Montpellier, Nîmes, France \\ ${ }^{3}$ Department of Neuroradiology, Montpellier University Hospital, Hôpital Gui-de-Chauliac, Montpellier, France
}

\section{Letter to Editor}

A 25-year-old woman with a history of obesity (body mass index of 33) and two uncomplicated caesarean deliveries presented with acute aphasia and right-sided hemiplegia (National Institute of Health Stroke Score of 22) nine days after the birth of her third child delivered by caesarean section. MRI showed an acute infarction in the left middle cerebral artery (MCA) territory with a DWI-Alberta stroke program early CT (ASPECT) score of 3, associated with a left M1 branch occlusion (Figure A-C). Mechanical thrombectomy (groin puncture 3:45 $\mathrm{h}$ after symptom onset) failed to recanalise the MCA after nine retrieval attempts (Figure D). CT performed five hours later showed a linear hypodensity of adipose origin (based on Hounsfield Unit analysis) crossing the infarction (with associated haemorrhagic transformation) suggesting fat embolism (Figure E-G).

Decompressive craniectomy was performed $24 \mathrm{~h}$ after symptom onset due to malignant MCA infarction. Two days later, she presented an acute respiratory distress syndrome. Thoracic and abdominal CT revealed multiple splenic, hepatic, and oemental infarctions (Figure $\mathrm{H}$ ) and bilateral pulmonary interstitial infiltrates (Figure I and J). Holter ECG, transthoracic and transoesophageal echocardiography were normal. Blood tests in search for prothrombotic, infectious and auto-immune abnormalities (including testing for antiphospholipid syndrome) were all normal except for the presence of haemolytic anaemia.

Four days after stroke onset, acute right leg ischemia occurred. Doppler ultrasound examination showed multiple arterial (bilateral radial, right ilio-femoral, left common and internal carotid arteries) and venous (right jugular and right superficial brachial veins) thrombosis. Serial fundus examinations and random skin biopsies failed to show fat emboli.

A diagnosis of fat embolism syndrome (FES) was made. Three months after brain infarction, modified Rankin score was 4 .

First described in 1962, FES is a rare entity, probably underdiagnosed due to incomplete clinical presentation including respiratory distress, skin rash, and neurological involvement (cognitive deficit, behaviour changes, decreased consciousness, and focal neurological signs). The most frequent aetiologies of FES are polytrauma, orthopaedic surgery, pelvic surgery, liposuction, pancreatitis, and sickle cell disease involving disruption of the adipose tissue or the bone marrow [1]. Transient retinal signs sometimes seen in FES can support the diagnosis and include cotton weal spots, macular oedema, haemorrhages, or glittering deposits of fatty emboli.

FES is a severe condition and can be fatal in $5-15 \%$ of cases [2]. There is no specific treatment for FES. However, supportive measures
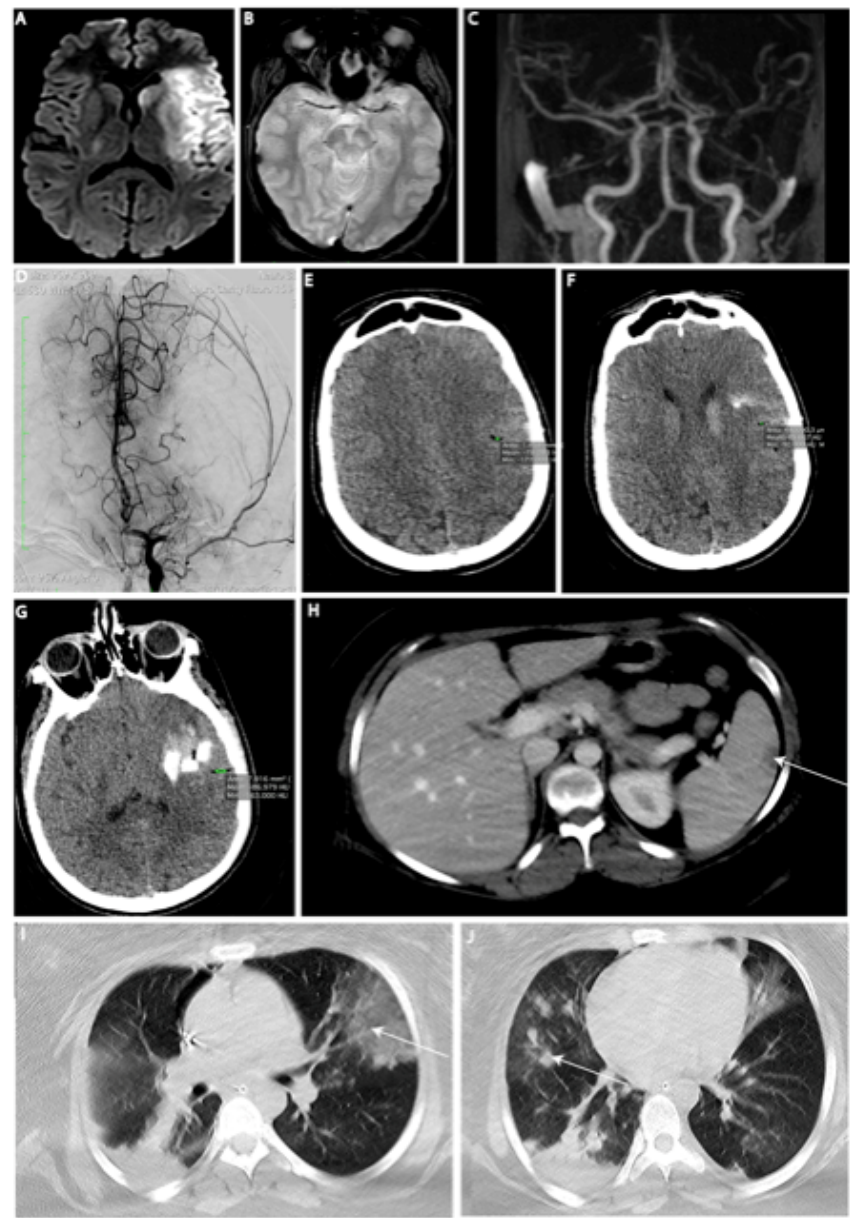

Figure 1. DWI showed left-sided middle cerebral artery infarction (A); $2^{*}$ of fat embolus (B); MRA showed left M1 branch occlusion (C); failed recanalisation of the left MCA (D); fat embolism seen as hypodensity (with Hounsfield Unit values corresponding to fat) on unenhanced CT with concomitant haemorrhage $(\mathrm{E}, \mathrm{F}, \mathrm{G})$; abdominal CT with multiple splenic, hepatic, oemental infarction $(\mathrm{H})$; thoracic $\mathrm{CT}$ with bilateral pulmonary interstitial infiltrates with ground-glass change (I) and nodular opacities (J)

*Correspondence to: Ioana Ion, Department of Neurology, CHU Nîmes, Hôpital Caremeau 4, Rue du Pr Debré 30029 Nîmes Cedex 4, France, Tel: (33) 4666832 61; Fax: (33) 4666840 16; E-mail: IOANAMARIA.ION@chu-nimes.fr

Key words: ischemic stroke, cerebral MRI, cerebral fat embolism, caesarean delivery

Received: August 20, 2018; Accepted: August 31, 2018; Published: September 03, 2018 
are required as clinical and radiological remission can be obtained in the majority of cases.

Radiological brain abnormalities in FES include multifocal smallsize infarctions, distal brain arteries occluded by adipose tissue (seen as hypodensity on CT with Hounsfield unit value between -110 and -50 , and as hyperintensity on unenhanced T1-weighted MRI and disappearing on fat-saturated T1-weighted imaging), and cerebral microbleeds (often very small and multiple, predominantly in the white matter especially involving the watershed areas and sometimes also involving the grey matter) $[3,4]$. In the exceptional FES cases with associated large cerebral artery occlusion, the presence of large foramen ovale or large pulmonary shunts was thought to be implicated in the pathophysiology of cerebral fat embolism, whereas small emboli pass through the pulmonary shunts, reaching the brain, where they are dissolved by activation of the tisular cerebral lipase [5,6].

Only a few cases of FES following caesarean delivery have been reported $[7,8]$. Most FES cases have been reported in young polytrauma patients with FES-related symptoms typically occurring 12-72 h after trauma $[9,10]$. The long delay before presenting clinical FES signs, the brain involvement as initial symptom, and the occlusion of a large cerebral artery (in the absence of foramen ovale or large pulmonary shunt) in our case were exceptional. The presence of fatty tissue (instead of a classical blood thrombus) occluding the MCA might explain the failed thrombectomy after several attempts in our case.

\section{Acknowledgements}

The authors thank Dr Sarah Kabani (Service de Biostatistique, Epidémiologie Clinique, Santé Publique et Innovation en Méthodologie (BESPIM), CHU de Nîmes, 4 Rue du Professeur Debré, 30029 Nîmes Cedex 09) for proofreading the manuscript.

\section{Contributors}

All authors contributed equally and agreed with the full content of the manuscript.

\section{Funding}

This research received no specific grant from any funding agency in the public, commercial or not-for-profit sectors.

\section{Patient consent}

Obtained.

\section{Ethics approval}

\section{CHU Nîmes.}

\section{References}

1. George J, George R, Dixit R (2013) Fat embolism syndrome. Lung India 30: 47 [Crossref]

2. Shaikh N (2009) Emergency management of fat embolism syndrome. J Emerg Trauma Shock 2: 29. [Crossref]

3. Kuo KH, Pan YJ, Lai YJ, Cheung WK, Chang FC, et al. (2014) Dynamic MR Imaging Patterns of Cerebral Fat Embolism: A Systematic Review with Illustrative Cases. Am J Neurorad 35: 1052-1057. [Crossref]

4. Rutman AM, Rapp EJ, Hippe DS, Vu B, Mossa-Basha M (2017) T2*-Weighted and Diffusion Magnetic Resonance Imaging Differentiation of Cerebral Fat Embolism From Diffuse Axonal Injury. J Comput Assist Tomogr 41: 877-883. [Crossref]

5. Avila JD (2017) Hypodense artery sign in cerebral fat embolism. Pract Neurol 17 304-305. [Crossref]

6. Barreto L, Amiel J-B, Dugard A (2013) The Rendu-Osler-Weber Disease Revealed by a Refractory Hypoxemia and Severe Cerebral Fat Embolism. Case Rep Crit Care 2013: 1-3. [Crossref]

7. Schrufer-Poland T, Singh P, Jodicke C (2014) Nontraumatic Fat Embolism Found Following Maternal Death after Cesarean Delivery. AJP Rep 05: e001-e005. [Crossref]

8. Karayel F, Arican N, Kavas G, Turan AA, Pakis I (2005) Maternal death due to nontraumatic fat embolism. J Forensic Sci 50: 1201-1203.

9. Gurd AR, Wilson RI (1974) The fat embolism syndrome. J Bone Joint Surg Br 56B: 408-416.

10. Campo-López C, Flors-Villaverde P, Calabuig-Alborch JR (2012) Fat embolism syndrome after bone fractures. Rev Clin Esp 212: 482-487. [Crossref]

Copyright: (C2018 Ion I. This is an open-access article distributed under the terms of the Creative Commons Attribution License, which permits unrestricted use, distribution, and reproduction in any medium, provided the original author and source are credited. 